\title{
A dietary pattern rich in olive oil and raw vegetables is associated with lower mortality in Italian elderly subjects
}

\author{
Giovanna Masala ${ }^{1}$, Marco Ceroti ${ }^{1}$, Valeria Pala ${ }^{2}$, Vittorio $\mathrm{Krogh}^{2}$, Paolo Vineis ${ }^{3}$, Carlotta Sacerdote ${ }^{3}$, \\ Calogero Saieva ${ }^{1}$, Simonetta Salvini ${ }^{1}$, Sabina Sieri ${ }^{2}$, Franco Berrino ${ }^{2}$, Salvatore Panico ${ }^{4}$, Amalia Mattiello ${ }^{4}$, \\ Rosario Tumino, Maria C. Giurdanella ${ }^{5}$, Christina Bamia ${ }^{6}$, Antonia Trichopoulou ${ }^{6}$, Elio Riboli ${ }^{7}$ and \\ Domenico Palli ${ }^{1} *$ \\ ${ }^{1}$ Molecular and Nutritional Epidemiology Unit, CSPO-Scientific Institute of Tuscany, Via Cosimo il Vecchio 2, 50139, Florence, \\ Italy \\ ${ }^{2}$ Epidemiology Unit, National Institute of Cancer, Via Venezian 1, 20133, Milan, Italy \\ ${ }^{3}$ Unit of Cancer Epidemiology, Department of Biomedical Sciences and Human Oncology, University of Turin, Via Santena 7, \\ 10126, Turin, Italy \\ ${ }^{4}$ Department of Clinical and Experimental Medicine, Federico II University, via S. Pansini 5, 80131, Naples, Italy \\ ${ }^{5}$ Cancer Registry, 'Civile M.P. Arezzo' Hospital, via Dante 109, 97100, Ragusa, Italy \\ ${ }^{6}$ Department of Hygiene and Epidemiology, University of Athens, 75 Mikras Asia street, 11527, Athens, Greece \\ ${ }^{7}$ Department of Epidemiology and Public Health, Imperial College, St Mary's Campus, Norfolk Place, London W2 1PG, UK
}

(Received 20 June 2006 - Revised 31 January 2007 - Accepted 5 February 2007)

\begin{abstract}
Dietary habits play an important role in healthy ageing. We have investigated the role of dietary patterns on overall mortality in a large series of Italian elderly, recruited in five EPIC cohorts in Northern (Varese and Turin), Central (Florence) and Southern Italy (Naples and Ragusa).A total of 5611 subjects (72.6\% women) aged 60 years or older, enrolled in 1993-1998, were prospectively followed (median 6.2 years), with 152 deaths (98 women). Four major dietary patterns were identified by using an exploratory factor analysis based on dietary information collected at enrolment. The associations between these dietary patterns and overall mortality were evaluated by Cox models adjusted for potential confounders. The 'Olive Oil \& Salad' pattern, characterised by a high consumption of olive oil, raw vegetables, soups and poultry, emerged as being inversely associated with overall mortality in both crude and adjusted models. After adjustment for gender, age and caloric intake, overall mortality was reduced by approximately $50 \%$ in the highest quartile and a significant trend emerged $(P=0.008)$. This association persisted after adjusting for several additional confounders (hazard ratio (HR) 0.50; $95 \%$ CI 0.29, 0.86; $P$ for trend $=0.02$ ). An association of the 'Pasta \& Meat' pattern (characterised by pasta, tomato sauce, red meat, processed meat, added animal fat, white bread and wine) with increased overall mortality was also suggested, but only for the highest quartile in a multivariate model. Dietary recommendations aimed at the Italian elderly population should support a dietary pattern characterised by a high consumption of olive oil, raw vegetables and poultry.
\end{abstract}

Dietary patterns: Elderly: Overall mortality: Vegetables: Olive oil

In the last decades, numerous studies have evaluated the relationship between the consumption of foods and food groups as well as the intake of macro- and micro-nutrients and the development of chronic diseases, particularly cancer and cardiovascular diseases. Dietary recommendations have been developed by several agencies (World Cancer Research Fund, 1997; Boyle et al. 2003; World Health Organization, 2003) based on available results. Fewer studies have focused on the effects of 'dietary patterns' on human health; this approach could allow the effects of several foods to be studied simultaneously and could bypass methodological problems related to the high inter-correlation among foods and nutrients in diet and multiple testing (Jacques \& Tucker, 2001). In addition, this methodology provides an overall description of dietary behaviours and may provide a more comprehensive approach to disease prevention by focusing on the entire diet rather than on just a single food or nutrient. Dietary patterns have been studied in relation to longevity (Trichopoulou et al. 1995; Huijbregts et al. 1997; Osler \& Schroll 1997; Kouris-Blazos et al. 1999; Lasheras et al. 2000). The majority of these studies evaluated the effect of the Mediterranean dietary pattern as defined by a priori scores that reflect the adherence to the essential components of the so-called Mediterranean diet (Trichopoulou et al. 1995, 2000) and have reported an inverse association of overall mortality with an increasing score. Another study, which also included two

\footnotetext{
Abbreviations: HR, hazard ratio; MET, metabolic equivalent.

* Corresponding author: Dr Domenico Palli fax, +39 055 32697829, email d.palli@cspo.it
} 
Italian cohorts of male subjects living in two rural areas of Northern and Central Italy (Huijbregts et al. 1997), found an inverse association between overall mortality and a healthy diet indicator based on the WHO dietary guidelines for the prevention of chronic disease.

Very recently, a modified Mediterranean score has been found to be associated with a reduced mortality among a large sample of elderly Europeans participating in the European Prospective Investigation into Cancer and Nutrition (EPIC) study (Trichopoulou et al. 2005).

Overall, different variants of the Mediterranean diet have been identified in Mediterranean countries (Slimani et al. 2002) even across geographical areas of the same country, while temporal changes in dietary habits have been described in Mediterranean countries, including Italy (Ferro-Luzzi \& Branca, 1995; Turrini et al. 2001). Thus, the identification of country-specific dietary patterns and the evaluation of their influence on health status and survival is of interest.

The aim of this study was to evaluate the effects of major dietary patterns, as identified with the a posteriori methodology based on observed correlation between foods (Pala et al. 2006), on the overall mortality in a cohort of 5611 Italian elderly subjects, who were recruited when aged 60 years or older in the Italian arm of the EPIC study (Palli et al. 2003). This analysis has been developed in the frame of the EPIC elderly project aimed to study the potential role of nutrition on the health and longevity of the European elderly as well as to examine the socio-economic and demographic factors that may affect dietary practices and, in turn, the health status of the elderly.

\section{Subjects and methods}

\section{Subjects}

In the period 1993-1998, the Italian section of the EPIC study completed the recruitment of 47749 adult volunteers (15 171 men and 32578 women) in four different areas covered by cancer registries: Varese (12083 volunteers) and Turin (10604) in the Northern part of the country, and Florence (13 597) and Ragusa (6403) in Central and Southern Italy, respectively. An associate centre in Naples enrolled 5062 women. Overall, 6031 of these volunteers were aged 60 years or older at enrolment. Detailed information about diet and lifestyle habits, anthropometric measurements and a blood sample were collected for each participant, after they had signed an informed consent form (Palli et al. 2003).

\section{Dietary habits}

The FFQ was specifically developed for Italian dietary habits and was tested in a pilot phase (Pisani et al. 1997). A detailed description of the EPIC-Italy FFQ has been reported elsewhere Pala et al. 2003). Briefly, dietary information on the frequency of consumption of more than 120 foods and beverages was collected, checked, coded and computerised by optical reading. In order to capture local dietary behaviours, two slightly different versions were developed and used in Naples and Ragusa. The questionnaires investigated dietary habits in the 12-month period prior to enrolment.
Food items were grouped for the purpose of identifying dietary patterns into food groups based on similarities in ingredients, nutrient profile or culinary usage. Additional subgroupings possibly representing alternative dietary habits were also retained whenever possible: thus the fish group was separated into tinned and fresh; bread was separated into wholemeal and white; and tomatoes and leafy vegetables were separated into cooked and raw. Overall, we had the following food groups for factor analysis: potatoes; leafy vegetables, cooked; leafy vegetables, raw; tomatoes, raw; tomatoes, cooked; root vegetables; cabbage; mushrooms; onion and garlic; mixed salad and mixed vegetables; legumes (pulses) including legumes for soup; other vegetables; citrus fruits; fresh fruit (noncitrus); seeds and nuts; milk; yoghurt; cheese; pasta and other grains (including polenta, couscous, etc.); rice; bread excluding wholemeal bread; wholemeal bread; beef; veal; pork; rabbit (farmed); chicken and turkey; other meat (goat, game, horse, lamb); processed meat; offal; fish, except tinned; crustaceans and molluscs; tinned fish; eggs; seed oils; olive oil; butter; margarine; other animal fats; sugar, honey and jam; chocolate-based confectionery; non-chocolate confectionery; ice-cream; cakes, sweet pies and pastries; puddings (non-milk based); patisserie and biscuits; fruit and vegetable juices; black coffee; coffee with milk; tea; wine; beer; spirits, fortified wines and aperitifs; soups (excluding legume soup); snacks; and pizza (Pala et al. 2006).

\section{Lifestyle habits}

A standardised lifestyle questionnaire (representing the Italian translation of a common EPIC-wide version and specifically printed in two versions for men and women) was also completed by each participant. Detailed information was collected on reproductive history, physical activity at work and in the household, and leisure-time activities (including walking, cycling and sports), smoking history, alcohol consumption, occupation, educational level and other socio-economic variables. An index of physical activity (PAL) was computed by applying specific MET (metabolic equivalents) to each of the leisure time and household activities, weighted by the number of hours spent on each specific activity as described elsewhere (Salvini et al. 2003). Appropriate MET were assigned to each activity according to the report of the Commission of European Community (1993) and with the data from the Italian LARN (Recommended Nutrient Intakes for the Italian population; Società Italiana di Nutrizione Umana, 1996).

A section of the EPIC lifestyle questionnaire requested information about previous diagnosis of myocardial infarction, stroke, diabetes, hypertension, hyperlipaemia, neoplasia and other selected illness.

\section{Anthropometry}

Weight, height, and waist and hip circumferences of each participant were measured by trained staff according to the international protocol of the EPIC study. BMI was calculated as weight (kg) divided by height $(\mathrm{m})$ squared. Subjects were classified into different BMI categories according to the WHO guidelines as follow: subjects with a BMI $<18.5$ were considered underweight, subjects with a BMI between 18.5 and 24.9 had normal weight; subjects with a BMI between 25 and 29.9 were 
considered overweight and subjects with a BMI $\geq 30$ or higher were classified as obese (World Health Organization, 2000). Waist circumference was considered as an indicator of central obesity based on the WHO cut-off points of 88 and $102 \mathrm{~cm}$ for females and males, respectively.

\section{Vital status follow-up}

The follow-up procedures have been implemented in each centre according to the guidelines prepared by a committee at the co-ordinating centre of the International Agency for Research on Cancer (IARC-Lyon). The ascertainment of vital status was carried out through the linkage with the local town offices and the local Mortality Registries, thereby identifying the deceased subject's date of death and allowing for the retrieval of the death certificate to identify the specific causes of death. The vital status was assessed for the Italian EPIC elderly at the following dates: 31 December 2001 for Varese and Florence, 30 June 2002 for Turin and Ragusa, and 30 June 2001 for Naples. Overall, 6031 EPIC-Italy elderly participants were followed from enrolment until death or end of follow-up whichever came first. At the end of the study period, 189 deceased subjects were identified, while the vital status information was not available for 32 subjects $(05 \%)$. For the purpose of the present analysis, we excluded 15 subjects who died within the first 12 months of follow-up and 405 subjects who at enrolment reported either a previous myocardial infarction, or a stroke or an invasive cancer (including 22 subjects who died during follow-up).

\section{Statistical analysis}

Dietary patterns were developed using exploratory factor analysis as previously described in detail in a dedicated paper (Pala et al. 2006). Briefly, exploratory factor analysis was applied to the pre-defined food groups in order to identify a few composite factors able to explain the maximum proportion of the variance present in the original groups. An orthogonal rotation procedure, the varimax rotation, was applied to simplify the factor structure and render it more interpretable. The graphical method known as the Scree test was used to identify the four factors to be retained (Cattell, 1966). Foods groups with an absolute loading $>0.30$ were considered to contribute importantly to that specific factor; a specific list showing the structure of the four rotated factors and the cumulative variance explained is given in Appendix 1. Factor scores for each pattern were calculated and assigned to each study subject. Scores were categorised in genderspecific quartiles based on the distribution in the entire EPIC-Italy elderly cohort.

Cox regression models, with the length of follow-up as the primary time variable, were used to estimate hazard ratios (HR) with $95 \%$ CI for the three upper quartiles in comparison with the lowest category of each factor score as reference. The multivariate analyses were all stratified by recruitment centre to account for possible differences in data collection and follow-up. We first estimated crude HR with $95 \% \mathrm{CI}$, and thereafter we estimated HR with $95 \%$ CI adjusted for sex, age (years) and log-transformed caloric intake (Model A). We also applied a second model (Model B) which, in addition, included terms for BMI (over and under 25), waist (continuous), smoking status (never smokers, ex-smokers and two categories for current smokers: 1-20 cigarettes/day, $>20$ cigarettes/day), years of education (continuous), civil status (married yes/no), hypertension at enrolment (yes/no), physical activity in the household and leisure-time activities as estimated by PAL (the highest tertile $v$. all others). All these characteristics have been shown to be related to both dietary patterns (Pala et al. 2006) and mortality. The role of selected medical conditions as reported by each participant at enrolment (diabetes and hyperlipaemia) was also evaluated but these were not added into the model because they did not materially modify the results.

The analyses were also carried out separately by gender and geographical area. Due to the small number of deaths available for each centre, the latter analysis was carried out by grouping the Northern (Varese and Turin) and CentralSouthern (Florence, Naples and Ragusa) centres.

All analyses were performed using SAS statistical software (Version 8.2; SAS Institute, Cary, NC, USA. A $P$ value of $<0.05$ was considered statistically significant.

\section{Results}

A total of 5611 subjects ( $72.6 \%$ women) were available for the analyses, with a median follow-up of 6.2 years. The distribution of EPIC-Italy elderly participants by gender and selected characteristics at enrolment is shown in Table 1. Most of the study subjects reported that they were married (68.9\% among women and $94.6 \%$ among men), while widows and widowers were 19.8 and $1.3 \%$, respectively; $34.8 \%$ of men and $47.6 \%$ of women reported having attended only primary school, whereas 8.4 and $8.0 \%$, respectively, had a university degree.

At enrolment, among men, 54.6\% were overweight and $15.5 \%$ obese. Among women, the proportion of overweight and obese subjects was 45.4 and $19.8 \%$, respectively. Never smokers were $27.1 \%$ for men and $66.2 \%$ for women. Most subjects were classified as sedentary according to an index of physical activity ( $87.3 \%$ males and $68.8 \%$ females). The proportions of subjects who, at enrolment, reported a previous diagnosis of hypertension, hyperlipaemia and diabetes were $35.3,34.9$ and $4.3 \%$, respectively.

A total of 35122 person-years (9382 for men) were available for analysis (Table 2); 11.402 for Varese, 10.768 for Florence, 6862 for Turin, 3454 for Naples and 2636 for Ragusa. The median age at enrolment was 62.3 years (range 60.072.2) among men and 62.7 (range 60.0-77.8) among women. Overall, 152 deceased subjects were included in the present analysis with a median age of 67.5 years at death (range 62.1-78.8). Among the 152 deceased subjects, 98 $(64.5 \%)$ were women with a median age of 68.5 years at death (range 62.1-78.8). Overall, $93(61 \cdot 2 \%)$ deceased subjects had been enrolled in the two Northern Italy centres (Table 2). The underlying causes of death were classified as follows: 83 deaths as due to cancer, 37 to cardiovascular disease and 32 to all other causes combined.

\section{Dietary patterns}

Four major dietary patterns, explaining $21 \%$ of the variance in the original dietary variables, have been identified (Pala et al. 
Table 1. Distribution of 5611 EPIC-Italy elderly participants, overall and by gender, according to selected characteristics (EPIC-Italy 1993-2002)

\begin{tabular}{|c|c|c|c|c|c|c|}
\hline \multirow[b]{2}{*}{ Characteristics } & \multicolumn{2}{|c|}{ Males } & \multicolumn{2}{|c|}{ Females } & \multicolumn{2}{|c|}{ Total } \\
\hline & $n^{\star}$ & $\%$ & $n$ & $\%$ & $n$ & $\%$ \\
\hline \multicolumn{7}{|l|}{ Civil status } \\
\hline Married & 1272 & $94 \cdot 6$ & 2779 & $68 \cdot 9$ & 4051 & $75 \cdot 3$ \\
\hline Widow/widower & 18 & 1.3 & 799 & $19 \cdot 8$ & 817 & $15 \cdot 2$ \\
\hline Divorced/unmarried & 54 & 4.0 & 458 & 11.4 & 512 & 9.5 \\
\hline \multicolumn{7}{|l|}{ Educational level } \\
\hline Primary school & 533 & $34 \cdot 8$ & 1935 & $47 \cdot 6$ & 2468 & $44 \cdot 1$ \\
\hline Secondary school & 338 & $22 \cdot 1$ & 863 & $21 \cdot 2$ & 1201 & 21.5 \\
\hline High school & 531 & 34.7 & 944 & $23 \cdot 2$ & 1475 & $26 \cdot 3$ \\
\hline University & 128 & 8.4 & 327 & $8 \cdot 0$ & 455 & $8 \cdot 1$ \\
\hline \multicolumn{7}{|l|}{ Smoking history } \\
\hline Never smoker & 409 & $27 \cdot 1$ & 2698 & $66 \cdot 2$ & 3107 & $55 \cdot 6$ \\
\hline Former smoker & 764 & $50 \cdot 6$ & 668 & $16 \cdot 4$ & 1432 & $25 \cdot 6$ \\
\hline Current smoker & 337 & $22 \cdot 3$ & 709 & $17 \cdot 4$ & 1046 & $18 \cdot 7$ \\
\hline \multicolumn{7}{|l|}{ BMI categories } \\
\hline Normal $(<25)$ & 455 & $29 \cdot 6$ & 1418 & $34 \cdot 8$ & 1873 & 33.4 \\
\hline Overweight (25-29.99) & 838 & $54 \cdot 6$ & 1851 & $45 \cdot 4$ & 2689 & 47.9 \\
\hline Obese $(\geq 30)$ & 243 & $15 \cdot 8$ & 806 & $19 \cdot 8$ & 1049 & $18 \cdot 7$ \\
\hline \multicolumn{7}{|l|}{ Central obesity (waist) $\dagger$} \\
\hline No & 1104 & $75 \cdot 2$ & 2676 & $66 \cdot 1$ & 3780 & $68 \cdot 6$ \\
\hline Yes & 364 & 24.8 & 1370 & 33.9 & 1734 & 31.5 \\
\hline \multicolumn{7}{|l|}{ Hypertension $\ddagger$} \\
\hline No & 1043 & $68 \cdot 0$ & 2579 & 63.5 & 3622 & $64 \cdot 7$ \\
\hline Yes & 491 & $32 \cdot 0$ & 1485 & $36 \cdot 5$ & 1976 & $35 \cdot 3$ \\
\hline \multicolumn{7}{|l|}{ Diabetesł } \\
\hline No & 1475 & $96 \cdot 0$ & 3896 & $95 \cdot 6$ & 5371 & $95 \cdot 7$ \\
\hline Yes & 61 & 4.0 & 179 & 4.4 & 240 & $4 \cdot 3$ \\
\hline \multicolumn{7}{|l|}{ Hyperlipaemiał } \\
\hline No & 1050 & 68.5 & 2596 & $63 \cdot 9$ & 3646 & $65 \cdot 2$ \\
\hline Yes & 484 & $31 \cdot 6$ & 1466 & $36 \cdot 1$ & 1950 & 34.9 \\
\hline \multicolumn{7}{|l|}{ Physical activity (PAL) } \\
\hline Sedentary $(<1 \cdot 6)$ & 1341 & $87 \cdot 3$ & 2804 & $68 \cdot 8$ & 4145 & 73.9 \\
\hline Moderately active $(1.6-1.74)$ & 127 & $8 \cdot 3$ & 1152 & $28 \cdot 3$ & 1279 & $22 \cdot 8$ \\
\hline Active $(\geq 1 \cdot 75)$ & 68 & 4.4 & 119 & 2.9 & 187 & $3 \cdot 3$ \\
\hline Total & 1536 & $27 \cdot 4$ & 4075 & $72 \cdot 6$ & 5611 & $100 \cdot 0$ \\
\hline
\end{tabular}

${ }^{*}$ Due to some missing data, not all numbers add up to the total.

†WHO cut off values: $\geq 88 \mathrm{~cm}$ women; $\geq 102 \mathrm{~cm}$ men.

$\ddagger$ Reported at baseline interview.

2006). Briefly, Pattern no. 1, labelled as 'Prudent' was characterised by a high consumption of cooked vegetables, legumes, fish, and seed oil as the main added fat. Pattern no. 2, labelled as 'Pasta \& Meat', was characterised by a high consumption of pasta and other grains, tomato sauce, red and processed meats, added animal fat, white bread and wine; on the other hand, this pattern showed a low consumption of yoghurt.
Pattern no. 3, named 'Olive Oil \& Salad', was characterised by a high consumption of olive oil as added fat, raw vegetables (tomatoes, leafy and root vegetables), soups and white meat (chicken and turkey). Pattern no. 4 labelled as 'Sweet \& Dairy' was characterised by high consumption of added sugar, cakes, ice-cream, coffee, eggs, butter, milk and cheese.

Table 2. Distribution of the 5611 EPIC-Italy elderly, person-years (PY) and number of deaths observed during the follow-up, overall and by gender and centre (EPIC-Italy 1993-2002)

\begin{tabular}{|c|c|c|c|c|c|c|c|c|c|}
\hline \multirow[b]{2}{*}{ EPIC-Italy } & \multicolumn{3}{|c|}{ Males } & \multicolumn{3}{|c|}{ Females } & \multicolumn{3}{|c|}{ Total } \\
\hline & Study subjects & PY & Deaths & Study subjects & PY & Deaths & Study subjects & PY & Deaths \\
\hline \multicolumn{10}{|l|}{ Northern } \\
\hline Turin & 539 & 3633 & 25 & 500 & 3229 & 7 & 1039 & 6862 & 32 \\
\hline Varese & 417 & 2121 & 9 & 1395 & 9281 & 52 & 1812 & 11402 & 61 \\
\hline \multicolumn{10}{|l|}{ Central } \\
\hline Florence & 374 & 2186 & 15 & 1444 & 8582 & 23 & 1818 & 10768 & 38 \\
\hline \multicolumn{10}{|l|}{ Southern } \\
\hline Naples & - & - & - & 558 & 3454 & 12 & 558 & 3454 & 12 \\
\hline Ragusa & 206 & 1442 & 5 & 178 & 1194 & 4 & 384 & 2636 & 9 \\
\hline Total & 1536 & 9382 & 54 & 4075 & 25740 & 98 & 5611 & 35122 & 152 \\
\hline
\end{tabular}


The distribution of study subjects in the quartiles of the four specific pattern scores is shown in Table 3, according to gender and other major individual characteristics. Subjects in the higher score quartiles of the 'Prudent' pattern were more frequently females, more educated, more likely to be single, former smokers and obese; they also reported more frequently a diagnosis of diabetes, hyperlipaemia or hypertension. Higher scores for the 'Pasta \& Meat' pattern were more likely among married males, current smokers, overweight or obese subjects. Subjects in the higher scores for the 'Olive oil \& Salad' pattern were more frequently males, married, with a higher school education, leaner and more physically active. Subjects in the higher scores of 'Sweet \& Dairy' pattern were more likely to have a higher education, to be more physically active and with a normal weight.

\section{Dietary patterns and overall mortality}

The 'Olive Oil \& Salad' pattern (Pattern no. 3) was inversely associated with all-cause mortality (Table 4). The univariate analysis, stratified by centre, showed a $56 \%$ lower risk of death from all causes in subjects in the highest quartile with respect to those in the lowest quartile of this score, with a statistically significant trend $(P=0 \cdot 001)$. After adjustment for gender, age and total caloric intake (Model A), the overall mortality risk was still reduced by approximately $50 \%$ in subjects classified in the upper quartile of this score. A statistically significant trend was evident across quartiles $(P=0 \cdot 008)$. This association persisted when we applied Model B including terms for several additional confounders. In separate analyses by gender, the association of Pattern no. 3 'Olive Oil \& Salad' with overall mortality showed similar results in the two sexes (based on the same models previously described), although the results did not reach statistical significance possibly because of smaller numbers.

In the analyses carried out separately for the two main geographical areas, by combining the two Northern (Turin and Varese) and the three Central Southern centres (Florence, Naples and Ragusa), a similar inverse association of 'Olive Oil \& Salad' pattern with overall mortality tended to be evident in both areas (data not shown).

We also explored the relationship between each food or food group contributing to the 'Olive Oil \& Salad' pattern with an absolute loading greater than $0 \cdot 30$ and overall mortality, with a series of analyses based on both Model A and the more complex Model B. While selected food groups were significantly associated with reduced mortality in the analyses based on the simpler Model A (white meat, $P=0.019$; root vegetables, $P=0 \cdot 004$ ), only one association persisted in the more complex Model B (root vegetables, $P=0 \cdot 02)$.

An increased overall mortality was observed among subjects classified in the highest quartile of the 'Pasta \& Meat' pattern (Pattern no. 2) when Model A was applied (HR $1.68 ; 95 \%$ CI 1.01, 2.80) but the P for trend across quartiles failed to reach statistical significance; this association tended to be even weaker when the more complex Model B was applied.

The other patterns 'Prudent' (Pattern no. 1) and 'Sweet \& Dairy ' (Pattern no. 4) were not significantly associated with mortality, either overall or in specific subgroups.

\section{Discussion}

This prospective study, carried out in a large multicentre cohort of 5611 Italian elderly subjects recruited within the EPIC-Italy project, showed an inverse association between overall mortality and a specific dietary pattern characterised by a high consumption of olive oil as added fat, raw vegetables (particularly lettuce and tomatoes), soups and poultry as animal protein source, after a 6-year follow-up. These results did not change substantially when men and women were analysed separately, or when the analyses were carried out separately for Northern and Central Southern Italian EPIC recruitment centres. The inverse association of the 'Olive Oil \& Salad' pattern with overall mortality is in agreement with the protective effect of several of its single food components. Olive oil is the most characteristic component of this pattern, and accumulating evidence suggests that it may have a role in the prevention of coronary heart disease and cancer, and may influence survival (Owen et al. 2000). Although olive oil is usually the main source of MUFA in the traditional Mediterranean diet (Dougherty et al. 1987) and although a high MUFA intake has been shown to improve the lipid profile, thus reducing cardiovascular risk (Trevisan et al. 1990), experimental studies indicate that the protective effect of olive oil is also related to a series of compounds with potent antioxidant properties, particularly phenols such as hydroxy-tyrosol (Visioli \& Galli, 2002; Salvini et al. 2006). The other relevant components of this pattern, leafy vegetables and tomatoes, are an important source of micronutrients with antioxidant properties, fibre and biologically active compounds. All of the latter provide a protective effect against a wide range of diseases, including cancer and cardiovascular diseases. While olive oil was the main added fat used in all the EPIC-Italy cohorts, subjects with a high score for this pattern were characterised by a particularly high consumption. As expected, olive oil consumption was strongly related to that of raw vegetables. The consumption of such vegetables together with olive oil might contribute to an improvement of the antioxidant status, because of the combination of the antioxidants from the vegetables and those from olive oil (especially when an extra-virgin olive oil is used). White meat is a relevant component of this pattern, and its consumption (in contrast to red meat) has been linked with a reduced risk of coronary heart disease $(\mathrm{Hu}$ et al. 1999, 2000). Moreover, white meat has not been directly linked to an increased cancer risk as has been found for other types of meat, particularly red meat and processed meats (World Cancer Research Fund, 1997; Norat et al. 2005). On the other hand, we have to consider that subjects in the highest quartile of this pattern were more likely to have a high educational level and normal weight, and to be physically active; all these conditions could contribute to increased survival. Although the association between the Olive Oil \& Salad pattern and overall mortality also persisted when adjusting for all these conditions, some residual confounding cannot be completely ruled out.

Pattern no. 1, labelled as the 'Prudent' pattern, might somehow appear similar to a Mediterranean dietary pattern, including a large variety of vegetables, mainly consumed cooked, in addition to legumes and fish, but it was not associated with a lower mortality. This pattern represents a low-cost version of 
Table 3. Percentage distribution of study participants according to selected demographic and lifestyle characteristics by quartiles (Q1-Q4) of the four dietary patterns identified in the EPIC elderly cohort (EPIC-Italy 1993-2002)

\begin{tabular}{|c|c|c|c|c|c|c|c|c|c|c|c|c|c|c|c|c|c|c|c|c|}
\hline \multirow[b]{2}{*}{ Dietary pattern } & \multicolumn{5}{|c|}{ Prudent } & \multicolumn{5}{|c|}{ Pasta \& Meat } & \multicolumn{5}{|c|}{ Olive Oil \& Salad } & \multicolumn{5}{|c|}{ Sweet \& Dairy } \\
\hline & \multicolumn{4}{|c|}{$\%$} & $\chi^{2} P$ & \multicolumn{4}{|c|}{$\%$} & $\chi^{2} P$ & \multicolumn{4}{|c|}{$\%$} & $\chi^{2} P$ & \multicolumn{4}{|c|}{$\%$} & $\chi^{2} P$ \\
\hline \multicolumn{21}{|l|}{ Sex } \\
\hline Male & 28.0 & $30 \cdot 7$ & 30.9 & $20 \cdot 0$ & & 6.5 & $16 \cdot 0$ & 28.9 & $58 \cdot 1$ & & $21 \cdot 7$ & $25 \cdot 2$ & 29.0 & 33.6 & & 28.5 & $28 \cdot 2$ & $26 \cdot 6$ & $26 \cdot 2$ & \\
\hline Female & 72.0 & $69 \cdot 3$ & $69 \cdot 1$ & $80 \cdot 0$ & $<0.0001$ & 93.5 & 84.0 & $71 \cdot 1$ & 41.9 & $<0.0001$ & $78 \cdot 3$ & 74.8 & 71.0 & $66 \cdot 4$ & $<0.0001$ & 71.5 & $71 \cdot 8$ & 73.4 & 73.8 & 0.4394 \\
\hline \multicolumn{21}{|l|}{ Civil status } \\
\hline Married & $73 \cdot 3$ & 77.4 & $79 \cdot 2$ & 71.3 & & 65.9 & $72 \cdot 4$ & $77 \cdot 4$ & $86 \cdot 1$ & & $69 \cdot 7$ & $75 \cdot 5$ & $77 \cdot 6$ & 78.6 & & 74.6 & $76 \cdot 0$ & 76.4 & $74 \cdot 2$ & \\
\hline Widow/widower & $17 \cdot 2$ & $13 \cdot 6$ & $12 \cdot 7$ & $17 \cdot 3$ & & $21 \cdot 0$ & $16 \cdot 9$ & $14 \cdot 0$ & 8.4 & & 19.6 & 14.5 & $13 \cdot 7$ & $12 \cdot 8$ & & $14 \cdot 3$ & $15 \cdot 1$ & $15 \cdot 4$ & $15 \cdot 9$ & \\
\hline \multicolumn{21}{|l|}{ Educational level } \\
\hline Primary school & 49.7 & $46 \cdot 3$ & $42 \cdot 8$ & 37.5 & & $42 \cdot 0$ & $45 \cdot 2$ & 44.9 & $44 \cdot 2$ & & 45.9 & $45 \cdot 2$ & 43.7 & 41.5 & & 50.9 & 44.9 & $41 \cdot 2$ & 39.3 & \\
\hline Secondary school & 21.5 & $20 \cdot 4$ & 20.9 & 23.0 & & 22.5 & $21 \cdot 3$ & 21.5 & 20.5 & & $22 \cdot 1$ & 18.6 & 22.6 & 22.4 & & $19 \cdot 6$ & $22 \cdot 2$ & $21 \cdot 0$ & $23 \cdot 1$ & \\
\hline High school & 23.7 & $26 \cdot 4$ & $26 \cdot 7$ & 28.6 & & $25 \cdot 4$ & $26 \cdot 1$ & $25 \cdot 8$ & $28 \cdot 0$ & & 23.7 & $26 \cdot 6$ & $26 \cdot 7$ & 28.4 & & $22 \cdot 9$ & 24.5 & 28.9 & 29.0 & \\
\hline University & $5 \cdot 1$ & 6.9 & 9.6 & $10 \cdot 9$ & $<0.0001$ & $10 \cdot 1$ & 7.4 & $7 \cdot 8$ & $7 \cdot 3$ & 0.1114 & 8.2 & 9.6 & 7.0 & $7 \cdot 7$ & 0.0060 & 6.6 & 8.4 & 8.9 & 8.6 & $<0.0001$ \\
\hline \multicolumn{21}{|l|}{ Smoking history } \\
\hline Never smoker & 57.9 & $55 \cdot 6$ & 54.6 & 54.4 & & 63,9 & 63,5 & 52,8 & 42,2 & & 54.1 & 56.9 & $57 \cdot 0$ & 54.5 & & 55.6 & 57.5 & 53.0 & $56 \cdot 4$ & \\
\hline Former smoker & $22 \cdot 8$ & $27 \cdot 1$ & $28 \cdot 8$ & 23.9 & & $21 \cdot 8$ & $20 \cdot 2$ & $26 \cdot 6$ & 34.0 & & $23 \cdot 2$ & $23 \cdot 3$ & $26 \cdot 1$ & 29.9 & & $26 \cdot 2$ & $26 \cdot 2$ & $26 \cdot 1$ & $24 \cdot 1$ & \\
\hline Current smoker & $19 \cdot 3$ & $17 \cdot 3$ & $16 \cdot 6$ & $21 \cdot 7$ & 0.0002 & $14 \cdot 3$ & $16 \cdot 3$ & $20 \cdot 6$ & $23 \cdot 8$ & $<0.0001$ & $22 \cdot 7$ & $19 \cdot 8$ & $16 \cdot 9$ & $15 \cdot 6$ & $<0.0001$ & $18 \cdot 2$ & $16 \cdot 3$ & $20 \cdot 9$ & 19.5 & 0.0475 \\
\hline \multicolumn{21}{|l|}{ BMI categories } \\
\hline Normal $(<25)$ & $36 \cdot 1$ & 35.4 & 33.5 & $28 \cdot 6$ & & $39 \cdot 1$ & 34.8 & $31 \cdot 0$ & $28 \cdot 6$ & & $33 \cdot 2$ & 34.9 & 34.6 & 30.9 & & $32 \cdot 0$ & 32.5 & 33.1 & 35.9 & \\
\hline $\begin{array}{l}\text { Overweight } \\
(25-29.99)\end{array}$ & $46 \cdot 3$ & $49 \cdot 6$ & $50 \cdot 2$ & $45 \cdot 6$ & & $45 \cdot 4$ & $46 \cdot 8$ & $48 \cdot 6$ & $50 \cdot 9$ & & $46 \cdot 3$ & $49 \cdot 2$ & $47 \cdot 8$ & $48 \cdot 3$ & & $46 \cdot 9$ & $48 \cdot 7$ & $49 \cdot 8$ & $46 \cdot 2$ & \\
\hline Obese $(\geq 30)$ & $17 \cdot 6$ & $15 \cdot 0$ & $16 \cdot 3$ & $25 \cdot 8$ & $<0.0001$ & $15 \cdot 5$ & 18.4 & $20 \cdot 4$ & 20.5 & $<.0001$ & 20.5 & $15 \cdot 9$ & $17 \cdot 6$ & 20.8 & 0.0062 & $21 \cdot 1$ & $18 \cdot 8$ & $17 \cdot 0$ & 17.9 & 0.0387 \\
\hline \multicolumn{21}{|c|}{ Central obesity (waist) ${ }^{\star}$} \\
\hline No & $72 \cdot 0$ & 74.6 & 71.9 & 55.8 & & $72 \cdot 8$ & $70 \cdot 1$ & $65 \cdot 2$ & $66 \cdot 1$ & & $62 \cdot 8$ & $72 \cdot 3$ & 69.9 & 69.3 & & 64.4 & $66 \cdot 6$ & $71 \cdot 6$ & 71.5 & \\
\hline Yes & 28.0 & $25 \cdot 4$ & $28 \cdot 1$ & $44 \cdot 2$ & $<0.0001$ & $27 \cdot 2$ & 29.9 & 34.8 & 33.9 & $<0.0001$ & $37 \cdot 2$ & $27 \cdot 7$ & $30 \cdot 1$ & 30.7 & $<0.0001$ & $35 \cdot 6$ & 33.4 & $28 \cdot 4$ & 28.5 & $<0.0001$ \\
\hline \multicolumn{21}{|l|}{ Hypertension† } \\
\hline No & 65.9 & 67.4 & 63.9 & 61.6 & & $64 \cdot 3$ & 64.9 & 64.6 & 64.9 & & 64.7 & $65 \cdot 3$ & 64.6 & 64.2 & & 63.3 & $63 \cdot 3$ & 65.7 & 66.4 & \\
\hline Yes & 34.1 & $32 \cdot 6$ & $36 \cdot 1$ & 38.4 & 0.0077 & $35 \cdot 7$ & 35.1 & 35.4 & $35 \cdot 1$ & 0.9884 & $35 \cdot 3$ & 34.7 & 35.4 & 35.8 & 0.9520 & $36 \cdot 7$ & $36 \cdot 7$ & 34.3 & 33.6 & 0.1828 \\
\hline Diabetes $\dagger$ & & & & & & & & & & & & & & & & & & & & \\
\hline No & $95 \cdot 8$ & 96.4 & 96.4 & 94.3 & & $96 \cdot 2$ & $96 \cdot 1$ & $95 \cdot 1$ & $95 \cdot 4$ & & $95 \cdot 7$ & $95 \cdot 6$ & $96 \cdot 1$ & $95 \cdot 4$ & & $92 \cdot 2$ & $95 \cdot 3$ & $97 \cdot 2$ & 98.1 & \\
\hline Yes & $4 \cdot 2$ & 3.6 & 3.6 & $5 \cdot 7$ & 0.0175 & 3.8 & 3.9 & 4.9 & $4 \cdot 6$ & 0.3678 & $4 \cdot 3$ & 4.4 & 3.9 & 4.6 & 0.8073 & $7 \cdot 8$ & 4.7 & $2 \cdot 8$ & 1.9 & $<0.0001$ \\
\hline Hyperlipaemia† & & & & & & & & & & & & & & & & & & & & \\
\hline No & 68.5 & $67 \cdot 0$ & 61.4 & 63.7 & & 58.5 & 63.7 & $67 \cdot 2$ & $71 \cdot 2$ & & 69.5 & 65.0 & 64.1 & $62 \cdot 1$ & & 59.4 & 63.4 & $67 \cdot 2$ & 70.6 & \\
\hline Yes & 31.5 & $33 \cdot 0$ & 38.6 & $36 \cdot 3$ & 0.0003 & 41.5 & $36 \cdot 3$ & $32 \cdot 8$ & $28 \cdot 8$ & $<0.0001$ & 30.5 & $35 \cdot 0$ & 35.9 & 37.9 & 0.0005 & $40 \cdot 6$ & $36 \cdot 6$ & $32 \cdot 8$ & 29.4 & $<0.0001$ \\
\hline Physical activity (PAL & & & & & & & & & & & & & & & & & & & & \\
\hline Sedentary $(<1 \cdot 6)$ & $76 \cdot 2$ & $75 \cdot 4$ & $73 \cdot 1$ & $70 \cdot 7$ & & $70 \cdot 9$ & $71 \cdot 7$ & $76 \cdot 2$ & 76.7 & & $76 \cdot 2$ & $75 \cdot 4$ & $73 \cdot 3$ & 70.5 & & 74.3 & 74.6 & $75 \cdot 3$ & 71.3 & \\
\hline $\begin{array}{l}\text { Moderately active } \\
(1.6-1.74)\end{array}$ & $21 \cdot 2$ & $21 \cdot 9$ & $22 \cdot 8$ & $25 \cdot 9$ & & $26 \cdot 0$ & $25 \cdot 4$ & $21 \cdot 4$ & $18 \cdot 4$ & & $21 \cdot 0$ & $21 \cdot 8$ & $23 \cdot 4$ & $25 \cdot 0$ & & $22 \cdot 7$ & $22 \cdot 3$ & $22 \cdot 0$ & $24 \cdot 2$ & \\
\hline Active $(\geq 1.75)$ & 2.6 & $2 \cdot 7$ & 4.7 & 3.4 & 0.0005 & 3.1 & 2.9 & 4.4 & 4.9 & $<0.0001$ & $2 \cdot 8$ & 2.8 & 3.3 & 4.5 & 0.0066 & 3.0 & $3 \cdot 1$ & $2 \cdot 7$ & 4.6 & 0.0567 \\
\hline
\end{tabular}

*WHO cut-off values: $\geq 88 \mathrm{~cm}$ women; $\geq 102 \mathrm{~cm}$ men.

† Reported at baseline interview. 
Table 4. Association between overall mortality and the four major dietary patterns (genderspecific quartiles) in 5611 elderly EPIC-Italy participants: crude and multivariate adjusted estimates of hazard ratios (HR) and $95 \% \mathrm{Cl}$ (EPIC-Italy 1993-2002)

\begin{tabular}{|c|c|c|c|c|c|c|}
\hline \multirow[b]{2}{*}{ Dietary pattern } & \multicolumn{2}{|c|}{ Crude* } & \multicolumn{2}{|c|}{ Model A† } & \multicolumn{2}{|c|}{ Model Bł } \\
\hline & $\mathrm{HR}$ & $95 \% \mathrm{Cl}$ & $\mathrm{HR}$ & $95 \% \mathrm{Cl}$ & $\mathrm{HR}$ & $95 \% \mathrm{Cl}$ \\
\hline \multicolumn{7}{|l|}{ No. 1: ‘Prudent' } \\
\hline I (low) & 1 & - & 1 & - & 1 & - \\
\hline II & 0.85 & $0.55,1.31$ & 0.88 & $0.57,1.36$ & 0.99 & $0.63,1.54$ \\
\hline III & 0.79 & $0.51,1.24$ & 0.88 & $0.56,1.40$ & 0.93 & $0.58,1.51$ \\
\hline IV & 0.76 & $0.45,1.30$ & 0.80 & $0.46,1.40$ & 0.85 & $0.47,1.53$ \\
\hline$P$ for trend & & 0.25 & & 0.45 & & 0.59 \\
\hline \multicolumn{7}{|c|}{ No. 2: 'Pasta \& Meat' } \\
\hline I (low) & 1 & - & 1 & - & 1 & - \\
\hline II & 1.03 & $0.66,1.60$ & $1 \cdot 14$ & $0.73,1.79$ & 1.07 & $0.67,1.70$ \\
\hline III & 0.87 & $0.54,1.39$ & 1.08 & $0.66,1.76$ & 0.99 & $0.59,1.64$ \\
\hline IV & $1 \cdot 19$ & $0.77,1.85$ & 1.68 & $1.01,2.80$ & 1.37 & $0.80,2 \cdot 34$ \\
\hline$P$ for trend & & 0.60 & & 0.08 & & 0.34 \\
\hline \multicolumn{7}{|c|}{ No. 3: ‘Olive Oil \& Salad’ } \\
\hline I (low) & 1 & - & 1 & - & 1 & - \\
\hline II & 0.74 & $0.48,1.13$ & 0.77 & $0.50,1.18$ & 0.78 & $0.50,1.21$ \\
\hline III & 0.67 & $0.44,1.05$ & 0.72 & $0.46,1.12$ & 0.76 & $0.48,1.20$ \\
\hline IV & 0.44 & $0.27,0.72$ & 0.49 & $0.29,0.82$ & 0.50 & $0.29,0.86$ \\
\hline$P$ for trend & & 0.001 & & 0.008 & & 0.02 \\
\hline \multicolumn{7}{|c|}{ No. 4: 'Sweet \& Dairy' } \\
\hline I (low) & 1 & - & 1 & - & 1 & - \\
\hline II & 0.84 & $0.54,1.31$ & 0.92 & $0.59,1.45$ & 0.90 & $0.56,1.45$ \\
\hline III & 0.71 & $0.45,1.13$ & 0.84 & $0.51,1.37$ & 0.87 & $0.52,1.45$ \\
\hline IV & 0.95 & $0.61,1.46$ & 1.34 & $0.80,2.27$ & 1.47 & $0.85,2.54$ \\
\hline$P$ for trend & & 0.68 & & 0.49 & & 0.25 \\
\hline
\end{tabular}

* Stratified by centre.

$\dagger$ Estimated by a series of Cox proportional models (stratified by centre) adjusted for sex, age (years) and caloric intake (log-transformed).

$\ddagger$ Estimated by a series of Cox proportional models (stratified by centre) adjusted for sex, age (years), BM (over and under 25), waist (continuous), smoking status (never smokers, ex-smokers and two categories for current smokers: 1-20 cigarettes/day, $>20$ cigarettes/day), years of education (continuous), civil status (married yes/no), hypertension at enrolment (yes/no), PAL (the highest tertile v. the others) and caloric intake (log-transformed).

the typical Southern diet, rich in fish, legumes and cooked vegetables (deep-fried or stir-fried), with seed oil replacing the traditional and more expensive olive oil (Pala et al. 2006). This pattern was the first to emerge in our analyses probably because it is relatively easy to identify a pattern characterised by seed oil consumption in a population largely using olive oil, particularly if the consumption of seed oil is strictly associated with other specific foods (such as fish). However, it was also shown that the 'Prudent' pattern was positively associated, particularly in women, with conditions such as hypertension, hypercholesterolaemia, overweight and obesity, conditions that might have directed this group of women towards the consumption of seed oils, as recommended, until recently, by medical doctors and in particular by cardiologists (Pala et al. 2006). Although all these conditions were controlled for in the statistical analyses, some residual confounding could have weakened the association of this pattern with overall mortality. In a previous analysis in the larger series of EPIC adults (Fusconi et al. 2003), seed oil consumption was significantly related to plasma levels of PUFA, and a correlation between fish consumption and $n-3$ fatty acids also emerged. The latter correlation (and the high consumption of cooked vegetables) 'a priori' might have suggested a protective effect of this pattern against overall mortality that however did not emerge in our data. It is of interest that the role of $n-3$ fats has been discussed recently
(Geleijnse et al. 2006; Hooper et al. 2006; MacLean et al. 2006).

The 'Pasta \& Meat' pattern is characterised by a high consumption of several traditional foods based on refined grains (particularly pasta and white bread), but also red meat, processed meat, and wine, the major source of alcohol in this population. Although it is characterised by some potentially 'protective' ingredients (such as tomato sauce), overall this pattern shares some characteristics (high intake of red meat and processed meat, consumption of refined cereal products and use of added animal fats) with the Western-style diet that have been associated with coronary heart diseases ( $\mathrm{Hu}$ et al. 2000), type II diabetes (van Dam et al. 2002) and colorectal cancer risk (Slattery et al. 1998; Fung et al. 2003). Red and processed meats have been linked to an increased risk of colorectal cancer, both in European (Norat et al. 2005) and in US prospective studies (Giovannucci et al. 1994). Moreover, studies carried out in vegetarian subjects have often shown reduced risks for both cardiovascular disease and all-cause mortality (Snowdon, 1988; Beeson et al. 1989; Fraser \& Shavlik, 1997), although a collaborative re-analysis of five prospective studies did not show a reduced risk for cerebrovascular disease and cancer at various sites in non-meat eaters (Key et al. 1999). In our cohort, this pattern emerged as characteristic of less educated men, across all study centres, and the adherence to this pattern increased with increasing 
BMI and cigarette smoking (Pala et al. 2006). This pattern tended to be associated with a higher mortality in a simplified model but, when a more complex model (including terms for several additional confounders such as education, BMI, waist circumference and smoking status) was applied, the association with overall mortality disappeared. It is noteworthy that, overall, this pattern was the only one with a factor loading negatively $(>0 \cdot 30)$; this specific food item was represented by yoghurt.

In our prospective study, dietary data were collected through validated dietary questionnaires specifically designed to capture local dietary habits in the Italian population, and local dietary patterns were derived with an a posteriori methodology based on observed correlation between foods. It is notable that while no specific association was evident in the Italian cohorts when the a priori modified Mediterranean score was applied in another analysis also involving several other countries (Trichopoulou et al. 2005), one of the four $a$ posteriori major patterns identified in the present paper, the 'Olive Oil \& Salad' pattern that shares some characteristics with the so-called Mediterranean diet, was clearly associated with a lower morality. It is possible that due to the large geographic variability of dietary habits across the Mediterranean countries together with temporal changes that have occurred more recently, a locally developed version of a Mediterranean pattern might play a more beneficial role in health status and survival. In addition, one has to consider that different questionnaires aimed to collect dietary information in separate countries might be characterised by different levels of detail and reliability.

Information on non-dietary variables that could be considered as potential confounders in the analyses were collected through a common questionnaire. The prevalence of a series of well-known non-dietary risk factors such as smoking, overweight and obesity is consistent with the results of other Italian studies focused on elderly subjects (Farchi et al. 2004). The adjustment for these above-mentioned factors has to be considered mandatory in studies investigating dietary influence on health and survival. In addition, standardised follow-up procedures have been developed in all Italian EPIC centres in order to ensure a complete mortality followup. In fact, the percentage of subjects for which vital status information was not available at the end of follow-up was very low.

The number of deaths available for the analysis was still relatively small, and this precluded the possibility of performing analyses according to specific causes of deaths. However, from a public health point of view, these results based on overall mortality appear particularly relevant.

Overall, our results suggest that a particular food pattern, characterised by a frequent consumption of raw vegetables, poultry (as source of animal protein) and olive oil (as added fat) can represent an appropriate diet for the elderly in order to improve survival and the maintenance of health.

\section{Acknowledgements}

The authors thank all study participants for their co-operation, and all the collaborators within the EPIC-Italy groups. We also are gratful to Francesco Sera and Lucia Castellucci (CSPO, Florence) for helpful suggestions for statistical analyses and for editorial assistance. EPIC-Italy has been financially supported by a generous grant from the Associazione Italiana per la Ricerca sul Cancro (AIRC-Milan) and by the European Union. The study has been conducted in co-operation with local organisations, particularly UNICOOP-Firenze, AVIS-Torino and AVIS-Ragusa. This study was also supported by the 'Quality of Life and Management of Living resources' Programme of the European Commission (DG Research, contract No QLK6-CT-2001-00241) for the project EPIC-Elderly, coordinated by the Department of Hygiene and Epidemiology, University of Athens Medical School. The funding source had no involvement in the study design, in the collection, analysis and interpretation of data, in the writing of the report and in the decision to submit the paper for publication. The authors are solely responsible for the publication, and the publication does not represent the opinion of the Community. The Community is not responsible for any use that might be made of data appearing in this work. All of the authors contributed to the formulation of the final manuscript. None of the authors had any conflict of interest.

\section{References}

Beeson WL, Mills PK, Phillips RL, Andress M \& Fraser GE (1989) Chronic disease among Seventh-day Adventists, a low-risk group. Rationale, methodology, and description of the population. Cancer 64, 570-581.

Boyle P, Autier P, Bartelink H, et al. (2003) European Code Against Cancer and scientific justification: third version. Ann Oncol 14, 973-1005.

Cattell RB (1966) The scree test for the number of factors. Multivariate Behav Res 1, 245-276.

Commission of European Communities (1993) Nutrient and Energy Intakes for the European Community. Reports of the Scientific Committee for Food (Thirty First Series). Luxembourg: Office for Official Publications of the European Communities.

Dougherty RM, Galli C, Ferro-Luzzi A \& Iacono JM (1987) Lipid and phospholipid fatty acid composition of plasma, red blood cells, and platelets and how they are affected by dietary lipids: a study of normal subjects from Italy, Finland, and the USA. Am J Clin Nutr 45, 443-455.

Farchi G, Brescianini S, Maggi S, Mariotti S, Scafato E, Di Carlo A, Baldereschi M \& Inzitari DILSA Group (2004) Risk factors and health determinants in older Italians. Aging Clin Exp Res 16, 3-12.

Ferro-Luzzi A \& Branca F (1995) Mediterranean diet. Italian-style: prototype of a healthy diet. Am J Clin Nutr 61, 1338-1345.

Fraser GE \& Shavlik DJ (1997) Risk factors for all-cause and coronary heart disease mortality in the oldest-old. The Adventist Health Study. Arch Intern Med 157, 2249-2258.

Fung T, Hu FB, Fuchs C, Giovannucci E, Hunter DJ, Stampfer MJ, Colditz GA \& Willett WC (2003) Major dietary patterns and the risk of colorectal cancer in women. Arch Intern Med 163, 309-314.

Fusconi E, Pala V, Riboli E, et al. (2003) Relationship between plasma fatty acid composition and diet over previous years in the italian centers of the European Prospective Investigation into Cancer and Nutrition (EPIC). Tumori 89, 624-635.

Geleijnse JM, Brouwer IA \& Feskens EJM (2006) Risks and benefits of omega 3 fats: health benefits of omega 3 fats are in doubt. $\mathrm{Br}$ Med J 332, 915.

Giovannucci E, Rimm EB, Stampfer MJ, Colditz GA, Ascherio A \& Willett WC (1994) Intake of fat, meat, and fiber in relation to risk of colon cancer in men. Cancer Res 54, 2390-2397. 
Hooper L, Thompson RL, Harrison RA, et al. (2006) Risks and benefits of omega 3 fats for mortality cardiovascular disease, and cancer: systematic review. Br Med J 332, 739-740.

Hu FB, Rimm EB, Stampfer MJ, Ascherio A, Spiegelman D \& Willett WC (1999) Dietary saturated fats and their food sources in relation to the risk of coronary heart disease in women. Am J Clin Nutr 70, 1001-1008.

$\mathrm{Hu}$ FB, Rimm EB, Stampfer MJ, Ascherio A, Spiegelman D \& Willett WC (2000) Prospective study of major dietary patterns and risk of coronary heart disease in men. Am J Clin Nutr 72, 912-921.

Huijbregts P, Feskens E, Rasanen L, Fidanza F, Nissinen A, Menotti A \& Kromhout D (1997) Dietary pattern and 20 year mortality in elderly men in Finland, Italy, and the Netherlands: longitudinal cohort study. Br Med J 315, 13-17.

Jacques PF \& Tucker KL (2001) Are dietary patterns useful for understanding the role of diet in chronic diseases? Am J Clin Nutr 73, 1-2.

Key TJ, Fraser GE, Thorogood M, et al. (1999) Mortality in vegetarians and non vegetarians: detailed findings from a collaborative analysis of 5 prospective studies. Am J Clin Nutr 70, Suppl. 3, 516S-524S.

Kouris-Blazos A, Gnardellis C, Wahlqvist ML, Trichopoulos D, Lukito W \& Trichopoulou A (1999) Are the advantages of the Mediterranean diet transferable to other populations? A cohort study in Melbourne, Australia. Br J Nutr 82, 57-61.

Lasheras C, Fernandez S \& Patterson AM (2000) Mediterranean diet and age with respect to overall survival in institutionalized, nonsmoking elderly people. Am J Clin Nutr 71, 987-992.

MacLean CH, Newberry SJ, Mojica WA, et al. (2006) Effects of omega-3 fatty acids on cancer risk: a systematic review. $J$ Am Med Assoc 295, 403-415.

Norat T, Bingham S, Ferrari P, et al. (2005) Meat, fish, and colorectal cancer risk: the European Prospective Investigation into cancer and nutrition. J Natl Cancer Inst 97, 906-916.

Osler M \& Schroll M (1997) Diet and mortality in a cohort of elderly people in a north European Community. Int $J$ Epidemiol 26, $155-159$.

Owen RW, Giacosa A, Hull WE, Haubner R, Wurtele G, Spiegelhalder B \& Bartsch H (2000) Olive-oil consumption and health: the possible role of antioxidants. Lancet Oncol 1, 107-112.

Pala V, Sieri S, Masala G, et al. (2006) Associations between dietary pattern and lifestyle, anthropometry and other health indicators in the elderly participants of the EPIC-Italy cohort. Nutr Metab Cardiovasc Dis 16, 186-201.

Pala V, Sieri S, Palli D, et al. (2003) Diet in the Italian EPIC cohorts: presentation of data and methodological issues. Tumori 89, 594-607.

Palli D, Berrino F, Vineis P, et al. (2003) A molecular epidemiology project on diet and cancer: the EPIC-Italy prospective study. Design and baseline characteristics of participants. Tumori 89, 586-593.

Pisani P, Faggiano F, Krogh V, Palli D, Vineis P \& Berrino F (1997) Relative validity and reproducibility of a food-frequency dietary questionnaire for use in the Italian EPIC centres. Int $J$ Epidemiol 26, Suppl. 1, S152-S160.

Salvini S, Saieva C, Ciardullo AV, et al. (2003) Physical activity in the EPIC-Italy centers. Tumori 89, 646-655.

Salvini S, Sera F, Caruso D, et al. (2006) Daily consumption of a high-phenol extra-virgin olive oil reduces oxidative DNA damage in post-menopausal women. Br J Nutr 95, 742-751.

Slattery ML, Boucher KM, Caan BJ, Potter JD \& Ma KN (1998) Eating patterns and risk of colon cancer. Am J Epidemiol 148, $4-16$.

Slimani N, Fahey M, Welch AA, et al. (2002) Diversity of dietary patterns observed in the European Prospective Investigation into Cancer and Nutrition (EPIC) project. Public Health Nutr 5, 1311-1328.

Snowdon DA (1988) Animal product consumption and mortality because of all causes combined, coronary heart disease, stroke, diabetes, and cancer in Seventh-day Adventists. Am J Clin Nutr 48, $739-748$.

Società Italiana di Nutrizione Umana (1996) Livelli di Assunzione Raccomandata di Energia e Nutrienti per la Popolazione Italiana $(L A R N)$. Roma: Istituto Nazionale della Nutrizione.

Trevisan M, Krogh V, Freudenheim J, Blake A, Muti P, Panico S, Farinaro E, Mancini M, Menotti A \& Ricci G (1990) Consumption of olive oil, butter, and vegetable oils and coronary heart disease risk factors. The Research Group ATS-RF2 of the Italian National Research Council. J Am Med Assoc 263, 688-692.

Trichopoulou A, Kouris-Blazos A, Wahlqvist ML, Gnardellis C, Lagiou P, Polychronopoulos E, Vassilakou T, Lipworth L \& Trichopoulos D (1995) Diet and overall survival in elderly people. Br Med J 311, 1457-1460.

Trichopoulou A, Lagiou P, Kuper H \& Trichopoulos D (2000) Cancer and Mediterranean dietary traditions. Cancer Epidemiol Biomarkers Prev 9, 869-873.

Trichopoulou A, Orfanos P, Norat T, et al. (2005) Modified Mediterranean diet and survival: EPIC-elderly prospective cohort study. $\mathrm{Br}$ Med J 330, 991.

Turrini A, Saba A, Perrone D, Cialfa E \& D’Amicis A (2001) Food consumption patterns in Italy: the INN-CA Study 1994-1996. Eur J Clin Nutr 55, 571-588.

van Dam RM, Rimm EB, Willett WC, Stampfer MJ \& Hu FB (2002) Dietary patterns and risk for type 2 diabetes mellitus in U.S. men. Ann Intern Med 136, 201-209.

Visioli F \& Galli C (2002) Biological properties of olive oil phytochemicals. Crit Rev Food Sci Nutr 42, 209-221.

World Cancer Research Fund (1997) Food, Nutrition and the Prevention of Cancer: A Global Perspective. Washington DC: American Institute for Cancer Research.

World Health Organization (2000) Obesity: Preventing and Managing the Global Epidemic. Report of a WHO Consultation. WHO technical report series no. 894. Geneva: WHO.

World Health Organization (2003) Diet, Nutrition and the Prevention of Chronic Disease. Report of a Joint WHO/FAO Expert Consultation. WHO technical report series no. 916. Geneva: WHO. 
Appendix 1. Factor analysis in the EPIC-Italy elderly cohort ( $n$ 5611): structures of the four retained rotated factors (dietary patterns $1-4)$ with foods and food groups ranked by their specific loading coefficients $(>0.30)$

\begin{tabular}{|c|c|c|c|}
\hline Dietary patterns & Foods and food groups & Loading coefficients & $\begin{array}{c}\text { Cumulative variance } \\
\text { explained }(\%)\end{array}$ \\
\hline \multirow[t]{12}{*}{ No. 1: 'Prudent' } & Other vegetables & & 0.69 \\
\hline & Legumes & & 0.62 \\
\hline & Leafy vegetables - cooked & 0.54 & \\
\hline & Onion, garlic & 0.53 & \\
\hline & Cabbage & 0.44 & 8 \\
\hline & Fish & 0.42 & \\
\hline & Crustaceans, molluscs & 0.42 & \\
\hline & Mushrooms & 0.37 & \\
\hline & Seed oil & 0.33 & \\
\hline & Fresh fruit (non-citrus) & 0.33 & \\
\hline & Tomatoes - cooked & 0.33 & \\
\hline & Nuts and seeds & 0.30 & \\
\hline \multirow[t]{9}{*}{ No. 2: 'Pasta \& Meat' } & Pasta \& other grains & 0.62 & \\
\hline & Beef & 0.61 & \\
\hline & Other animal fat & 0.59 & \\
\hline & Tomatoes - cooked & 0.50 & 13 \\
\hline & Wine & 0.49 & \\
\hline & White bread & 0.44 & \\
\hline & Processed meat & 0.43 & \\
\hline & Pork & 0.38 & \\
\hline & Yoghurt & -0.30 & \\
\hline \multirow[t]{6}{*}{ No. 3: 'Olive Oil \& Salad' } & Olive oil & 0.77 & \\
\hline & Tomatoes - raw & 0.67 & \\
\hline & Leafy vegetables - raw & 0.62 & 17 \\
\hline & Root vegetables & 0.55 & \\
\hline & Soups & 0.33 & \\
\hline & Chicken and turkey & 0.31 & \\
\hline \multirow[t]{11}{*}{ No. 4: 'Sweet \& Dairy' } & Sugar, honey, jam & 0.46 & \\
\hline & Ice-cream & 0.44 & \\
\hline & Chocolate-based confectionery & 0.43 & \\
\hline & Cakes and puddings & 0.43 & \\
\hline & Coffee & 0.39 & 21 \\
\hline & Processed meat & 0.36 & \\
\hline & Eggs & 0.35 & \\
\hline & Milk & 0.34 & \\
\hline & Butter & 0.33 & \\
\hline & Cheese & 0.31 & \\
\hline & Patisserie and biscuits & 0.31 & \\
\hline
\end{tabular}

